\title{
SISTEM REKOMENDASI FILM BERBASIS JEJARING SOSIAL (TWITTER) MENGGUNAKAN IBM BLUEMIX
}

\author{
Sarosa Castrena Abadi'), Muhammad Ayat Hidayat ${ }^{2)}$, Purwandito Tulus Asmoro ${ }^{3)}$ \\ ${ }^{1,3)}$ Teknik Listrik Politeknik Enjinering Indorama \\ 2) Teknik Elektro Universitas Negeri Makassar \\ 1,3) Jl. Kembang Kuning, Kabupaten Purwakarta, Jawa Barat \\ 2) Jl. Daeng Tata Raya Parang Tambung, Kota Makassar, Sulawesi Selatan \\ e-mail: sarosa.castrena@pei.ac.id ${ }^{1)}$, Muhammad.ayat.hidayat@gmail.com²), purwandito@pei.ac.id ${ }^{3)}$
}

\begin{abstract}
ABSTRAK
Perkembangan industri hiburan seperti film saat ini sangat begitu pesat dan bervariasi, hal tersebut seringkali membingungkan para penikmat film dalam menentukan film yang sangat direkomendasikan, solusi atas permasalahan tersebut adalah suatu sistem rekomendasi film yang dapat memberikan rekomendasi film-film yang berkualitas untuk ditonton oleh penikmat film berdasarkan rating film tersebut.

Twitter jejaring sosial favorit yang masih sering digunakan oleh masyarakat saat ini untuk menuliskan pikiran, perasaan maupun aspirasi dari setiap user, pada sistem ini cuitan twitter berfungsi sebagai data input yang dapat diolah menjadi suatu data yang lebih bernilai seperti rating. Penelitian ini dibahas sistem rekomendasi film berdasarkan rating dari komentar komentar twitter menggunakan ibm bluemix dengan algoritma Support Vector Machine. Hasil Pengujian memberikan keluaran berupa rating, dimana nilai yang dihasilkan cenderung mendekati nilai rating dari situs rating film yang sudah popular dan terpercaya.
\end{abstract}

Kata Kunci: Rekomendasi, Twitter, IBM Bluemix, Machine Learning, Support Vector Machine

\begin{abstract}
The development of the entertainment industry as the movie is currently very rapid and varied, it often confuses the movie connoisseurs in determining the movie is highly recommended, the solution to the problem is a movie recommendation system that can recommend quality movies to be watched by movie connoisseurs based on the movie rating.

Twitter is a favorite social network that is still used by today's people to write the thoughts, feelings and aspirations of each user, on this system Twitter tweets serve as input data that can be processed into a more valuable data such as rating. This research discussed the film recommendation system based on the rating of Twitter comments using IBM Bluemix with the Support Vector Machine algorithm. The test results provide a rating output, where the resulting value tends to approach the rating value of the already popular and trusted film rating site.
\end{abstract}

Keywords: Recommendation, Twitter, IBM Bluemix, Machine Learning, Support Vector Machine

\section{Pendahuluan}

Perkembangan industri hiburan seperti film saat ini sangat begitu pesat dan bervariasi, hal tersebut seringkali membingungkan para penikmat film dalam menentukan film yang sangat direkomendasikan, solusi atas permasalahan tersebut adalah suatu sistem rekomendasi film yang dapat memberikan rekomendasi film-film yang berkualitas untuk ditonton oleh penikmat film berdasarkan rating film.

Pertumbuhan jejaring sosial saat ini sangat pesat perkembangannya, salah satunya Twitter jejaring sosial yang digunakan untuk menuliskan ide, pikiran, perasaan seseorang tentang sesuatu hal dimana jumlah katanya dibatasi. Twitter mulai dari tahun 2006 pertumbuhannya sangat cepat, Twitter tercatat mengirim lebih dari 200 juta tweet setiap hari [1].

Text mining merupakan salah satu teknik data mining yang digunakan untuk mengekstraksi informasi dari berbagai pola yang berada di dalam dokumen-dokumen teks melalui analisis tertentu [1]. Analisis yang digunakan dalam proses text mining yaitu analisis sentimen. Hasil dari text mining dijadikan studi mengenai pendapat, penilaian, sentimen, tingkah laku dan perasaan orang-orang terhadap suatu entitas seperti tokoh individu, organisasi, layanan, produk, topik, acara, masalah beserta atribut-atributnya [1]. Analisis sentimen berfungsi untuk menganalisis komentar-komentar dari Twitter yang kemudian dikonversi menjadi sesuatu informasi yang lebih bermanfaat seperti rating [1]. Rating digunakan oleh sistem rekomendasi (recommendation system) untuk membantu user memilih sesuatu sesuai dengan kebutuhan atau ketertarikan user oleh sebab itu rating merupakan komponen yang sangat penting dalam sistem rekomendasi. Berdasarkan permasalahan tersebut penelitian ini akan 
membahas mengenai perancangan sistem rekomendasi film berdasarkan rating dari komentar- komentar twitter menggunakan IBM Bluemix.

\section{TINJAUAN PUSTAKA DAN DASAR TEORI}

\section{A. Sistem Rekomendasi (Recommendation System)}

Sistem Rekomendasi merupakan suatu aplikasi yang berfungsi untuk memberikan suatu informasi mengenai saran atau penilaian suatu hal yang akan bermanfaat bagi user [2]. Rekomendasi dan penilaian tersebut dapat diimplementasikan pada proses pengambilan keputusan seperti kandidat pemenang audisi, peralatan yang direkomendasikan kualitasnya atau film apa direkomendasikan untuk ditonton.

Secara sederhana suatu rekomendasi personal ditawarkan dalam bentuk ranking, proses penetuan ranking dilakukan dengan membuat suatu prediksi yang berasal dari penilaian user. Penilaian tersebut dapat berupa penilaian rating maupun kualitas suatu item. Selain rekomendasi personal terdapat rekomendasi jenis non personal, rekomendasi non personal biasanya ditampilkan di majalah atau koran, contohnya seperti rekomendasi 5 gadget pilihan dan terlaris [2].

\section{B. Twitter}

Twitter dibuat oleh Jack Dorsey pada tahun 2006 dan release pertama pada bulan Juli 2006 yang masih banyak penggunanya hingga saat ini [1]. Twitter memiliki fitur yang dapat membantu developer mengembangkan aplikasi sesuai dengan kebutuhannya yaitu Application Programming Interface (API)[1]. Ada beberapa jenis API pada Twitter yang dapat digunakan antara lain [1]:

1. Twitter REST API

Twitter REST API terdiri dari 2 komponen yang pertama Twitter REST yang berfungsi untuk memberikan core data dan core twitter objects kemudian komponen yang kedua Twitter Search berfungsi untuk melakukan pencarian mengenai instance dari suatu objek maupun mencari trend di Twitter [1].

2. Twitter Streaming API

Twitter Streaming API ini digunakan untuk pengumpulan dan eksplorasi data, melalui API ini informasi didapatkan secara realtime dan jumlahnya sangat tinggi [1].

\section{Text Mining}

Proses penggalian dan eksplorasi data pada Text mining berasal dari dokumen bertujuan untuk mencari katakata yang mewakili isi dokumen selanjutnya akan dianalisa keterkaitan untuk setiap dokumen. Text mining bertujuan untuk menggali informasi yang bermanfaat dari sumber data yang berupa dokumen dengan format yang tidak terstruktur [3].

Text mining terdiri dari beberapa tahap yaitu tahap pengolahan teks (tokenisasi) merupakan proses memecah kalimat menjadi kata, tahap kapitalisasi yaitu mengkonversi huruf kapital dan menghapus tanda baca, tahap stemming yaitu mengubah kata imbuhan menjadi kata dasar, tahap filtering teks yaitu proses mengelompokkan suatu kata dan dihitung jumlahnya, tahap pencarian pola (pattern discovery) yaitu proses pencarian pola pada suatu informasi, tahap evaluasi yaitu tahap penafsiran pola yang telah didapat [3].

\section{Analisis Sentimen}

Teknik atau analisis yang digunakan untuk mencari atribut dari suatu objek seperti kualitas, fitur dan kelemahan menjadi suatu hasil berupa pendapat atau penilaian disebut analisis sentiment [4]. Analisis sentimen bertugas mengklasifikasikan data untuk memberikan informasi bahwa penilaian yang dinyatakan untuk dokumen tersebut apakah positif, negatif atau netral [4]. Analisis sentimen diklasifikasikan menjadi dua kelompok yaitu klasifikasi subjektivitas (subjectivity classification) dan klasifikasi analisis sentimen. Analisis sentiment ini merupakan proses yang penting dalam menentukan apakah dokumen tersebut memiliki opini yang bernilai positif, negatif maupun netral [4].

\section{E. Algoritma Support Vector Machine}

Support Vector Machine (SVM) merupakan algoritma yang menggunakan ruang hipotesis berupa fungsi-fungsi linier dalam sebuah ruang ciri (feature space) berdimensi tinggi, dilatih dengan algoritma pembelajaran yang didasarkan pada teori optimasi dengan mengimplementasikan bias pembelajaran yang berasal dari teori pembelajaran statistik [5].

Support Vector Machine sering digunakan dalam proses pattern recognition [6]. SVM berfungsi untuk 
menghasilkan sebuah model data yang dapat memprediksi nilai target dari data pengujian melalui atribut-atribut data pengujian [7].

\section{F. IBM Bluemix}

IBM Bluemix adalah platform cloud yang dikembangkan oleh IBM [8]. Mendukung beberapa bahasa pemrograman serta terintegrasi DevOps yang berfungsi untuk membangun, menjalankan, menyebarkan dan mengelola aplikasi cloud. Bluemix teknologi Cloud Foundry dan berjalan pada infrastruktur SoftLayer.

1. Insight for Twitter Services

Layanan ini menyediakan sentimen dan pengkayaan lain untuk beberapa bahasa menggunakan fitur natural language dari IBM Social Media Analytics. Pengolahan real-time data stream dilakukan melalui service insight for twitter dan dikonfigurasi melalui serangkaian parameter request dan kata kunci. Pada service insight for twitter terdapat RESTful API yang berfungsi untuk menyesuaikan pencarian dan Re-Tweet dengan format JSON.

2. Services PHP

Merupakan layanan pada IBM Bluemix yang digunakan untuk mengembangkan, menyebarkan, dan skala aplikasi web PHP dengan mudah.

3. Services ClearDB

ClearDB merupakan layanan database yang handal untuk aplikasi MySQL. ClearDB dibangun menggunakan MySQL 5.5, dan ClearDB tidak memerlukan penggunaan mesin khusus atau perubahan pada kode kita.

\section{METODE PENELITIAN}

Sistem ini terdiri dari 4 bagian seperti yang ditunjukkan oleh Gambar2 .

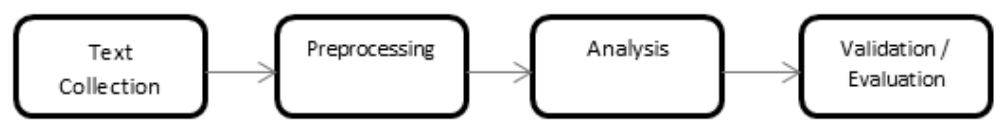

Gambar 1. Skema kerja sistem

\section{A. Text Collection}

Text Collection dilakukan dengan menggunakan Service Insight for Twitter bluemix dengan penambahan filter berdasarkan keyword "I rated". Service Insight for twitter bersifat realtime dan jumlah tweet yang didapatkan melalui Service Insight for twitter berjumlah 80 ribu tweet namun pada penelitian ini data yang digunakan hanya 319 tweet dikarenakan hanya tweet mengenai film yang release di tahun 2016. Data tersebut selanjtnya akan dimasukkan kedalam database clearDB dan kemudian akan diolah ditahap preprocessing menggunakan service PHP di IBM Bluemix.

\section{B. Preprocessing}

Preprocessing merupakan tahapan untuk menghilangkan informasi yang tidak penting, membuat kata yang seragam dan membuat volume kata menjadi berkurang [9], yaitu dengan mengkonversi struktur data dari suatu informasi kedalam format tertentu dapat berbentuk kumpulan pernyataan yang selanjutnya akan diklasifikasikan. pada penelitian ini kata yang bersifat penilaian digunakan sebagai elemen pembobotan kemudian setelah itu dilakukan cleansing untuk membuang kata - kata yang tidak diperlukan untuk dijadikan data set.

\section{Metode Perhitungan Rating}

Penghitungan rating pada SVM untuk setiap twitnya memiliki keluaran berupa bilangan desimal, nilai tersebut kemudian diklasifikasikan menjadi tweet positif, netral dan negatif di dalam sebuah tabel konversi nilai seperti yang di tunjukkan oleh Tabel I. 
Tabel I. Tabel Konversi Nilai

\begin{tabular}{cc}
\hline Klasifikasi & Batas Nilai \\
\hline Twit Positif & $X \geq 7$ \\
Twit netral & $5<X \leq 6$ \\
Twit negatif & $X \leq 5$ \\
\hline
\end{tabular}

Apabila twit tersebut telah terklasifikasi menjadi positif, netral atau negatif, selanjutnya dibuatlah rating. Rating dibuat dalam skala 10, dengan rumus sebagai berikut:

$$
\text { Rating }=\frac{\text { Jumlah Twit Positif }+ \text { Jumlah Twit Netral }}{\text { Jumlah Total Twit }} \times 10
$$

D. Evaluasi

Nilai Rating yang diperoleh berikutnya akan di evaluasi dengan membandingkan nilai rating dari sistem dengan rating dari situs rating popular. Nilai rating akan menjadi suatu rekomendasi bagi user. Validation model diukur melalui perhitungan akurasi data. Berikut rumus akurasi data:

$$
\text { Akurasi }=\frac{\text { Jumlah Klasifikasi Benar }}{\text { Jumlah Data Uji Coba }} \times 100 \%
$$

\section{HASIL DAN PEMBAHASAN}

Proses pengujian dari system rekomender film ini, terbagi menjadi beberapa tahap yaitu :

1. Melakukan proses cleanse dan import data tweet ke dalam database cleardb di IBM Bluemix. Hasil dari tahap ini adalah data movies tahun 2016 untuk semua genre.

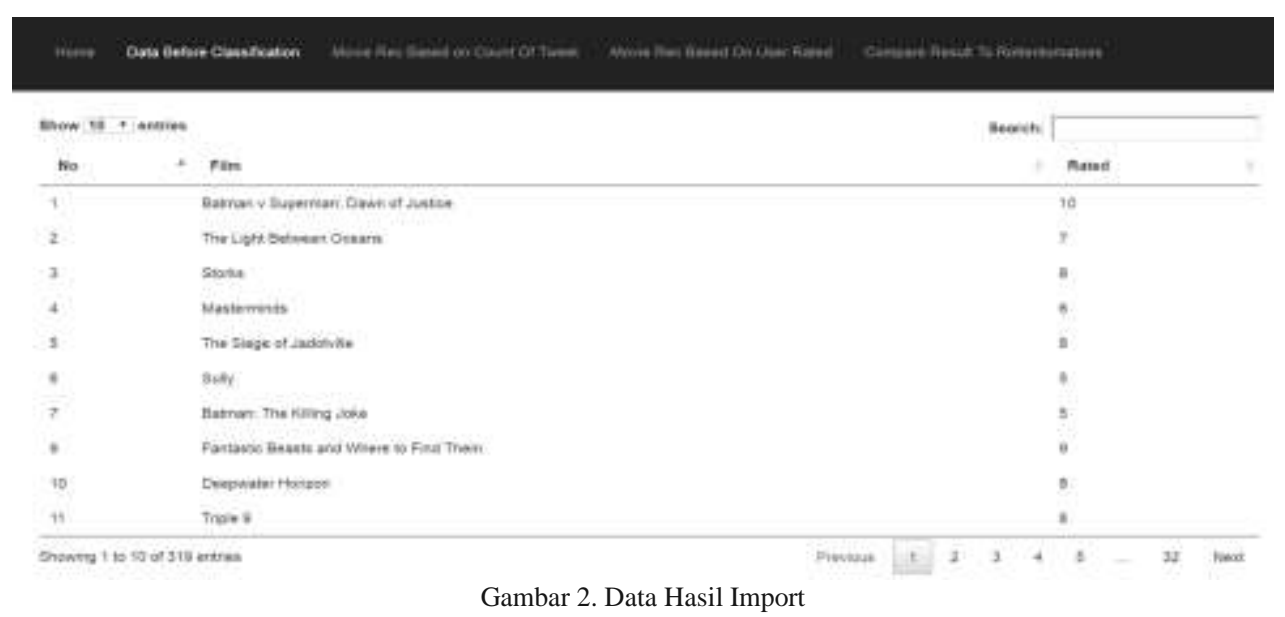

Proses cleansing datanya meliputi penghapusan tautan, hashtag, kata (2016) serta kata "I rated". Sehingga karakter yang tersisa adalah nama film serta rating yang diberikan oleh user tersebut.

2. Melakukan proses klasifikasi terhadap data yang telah di import menggunakan list film action yang di rilis tahun 2016. Hasil dari tahap ini adalah data film 2016 yang kategori action. 


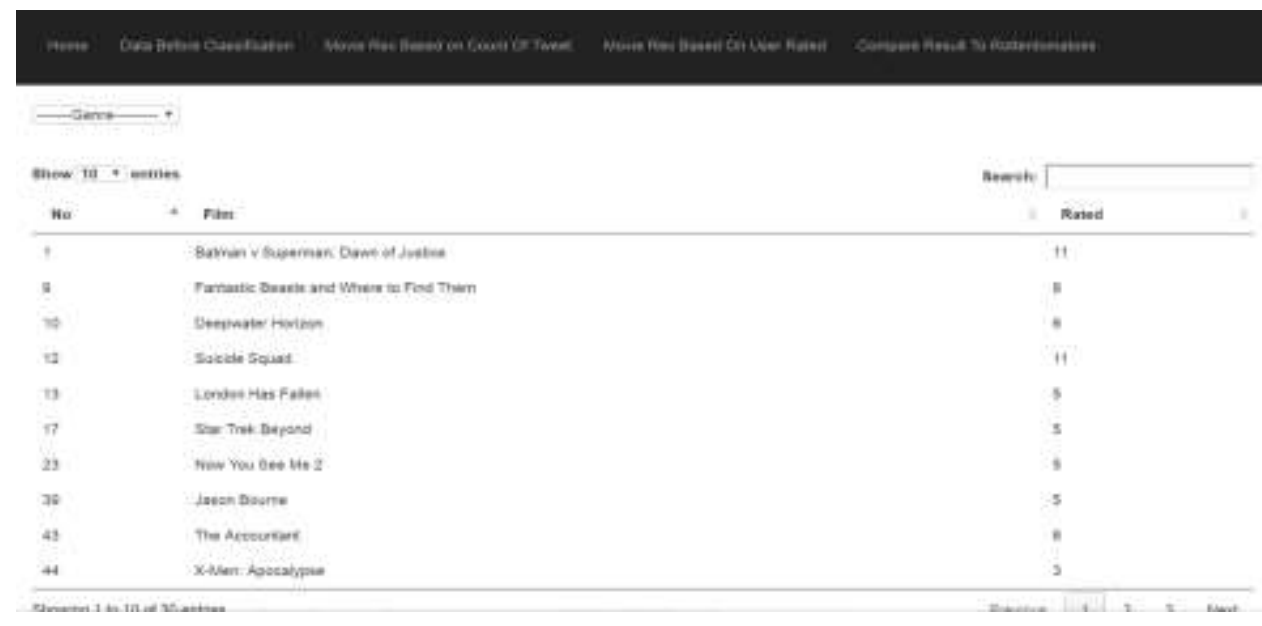

Gambar 3. Data Hasil Klasifikasi

3. Melakukan perhitungan rating menggunakan rumus SVM, terhadap data yang telah diklasifikasikan. Hasil dari tahap ini adalah data fillm beserta dengan rating yang diberikan.
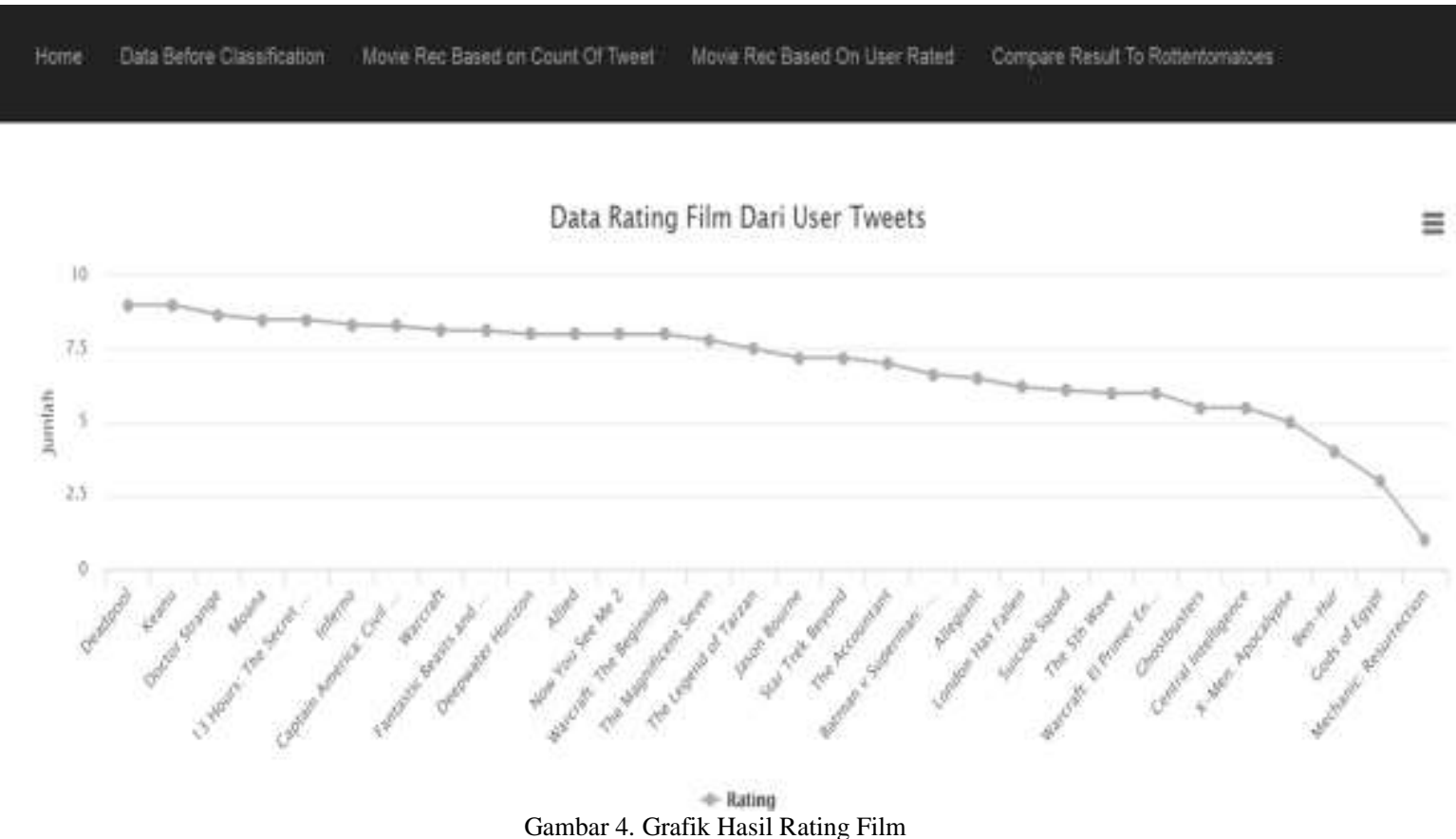

4. Tahap berikutnya adalah melakukan perbandingan antara data rating yang didapatkan menggunakan svm dengan rating film yang didapatkan dari website film rekomender terpercaya yaitu rottentomatoes.com. Metode yang digunakan dengan menghitung selisih dari kedua rating tersebut. Jika kriteria melebihi 2 maka rating film tersebut dikatakan tidak sesuai, dan jika kurang atau sama dengan 2 maka rating film tersebut dikatakan sesuai. Dua (2) merupakan margin untuk menentukan apakah rating film yang kita dapatkan sesuai dengan rating yang berasal dari rottentomatoes.com. Hasil dari tahap ini adalah jumlah rating film yang sesuai dan jumlah rating film yang tidak sesuai

Tabel 2. Hasil Perbandingan Rating

\begin{tabular}{ccc}
\hline Nama Film & Rating Sistem & Rating Rotten \\
\hline Keanu & 9 & 6,4 \\
Deadpool & 9 & 7 \\
Doctor Strange & 8,667 & 7,3 \\
Moana & 8,5 & 7,9 \\
13 Hours:The Secret Soldiers of Benghazi & 8,5 & 5,5 \\
Inferno & 8,3 & 4,5 \\
Captain America:civil war & 8,28 & 7,6 \\
Warcraft & 8,14 & 4,2 \\
\hline
\end{tabular}




\begin{tabular}{ccc}
\hline Fantastic & 8,12 & 6,8 \\
Allied & 8 & 6,2 \\
Deepwater Horizon & 8 & 7 \\
Now You see me 2 & 8 & 4,9 \\
The magnificent seven & 7,8 & 6 \\
The legend of Tarzan & 7,5 & 5,1 \\
Star Trek Beyond & 7,2 & 6,9 \\
Jason Bourne & 7,2 & 5,9 \\
The Accountant & 7 & 5,6 \\
Batman vs Superman & 6,636 & 4,9 \\
Allegian & 6,5 & 4,1 \\
London Has Fallen & 6,2 & 3,9 \\
Suicide Squad & 6,09 & 4,7 \\
The 5 $5^{\text {th } W a v e ~}$ & 6 & 4,2 \\
Central Intelligence & 5,5 & 5,7 \\
GhostBusters & 5,5 & 6,5 \\
X-Men:Apocalypse & 5 & 5,6 \\
Ben-Hur & 4 & 4,6 \\
Gods of Egypt & 3 & 3,5 \\
Mechanic Resurrection & 1 & $4,2 \mathrm{~s}$ \\
\hline
\end{tabular}

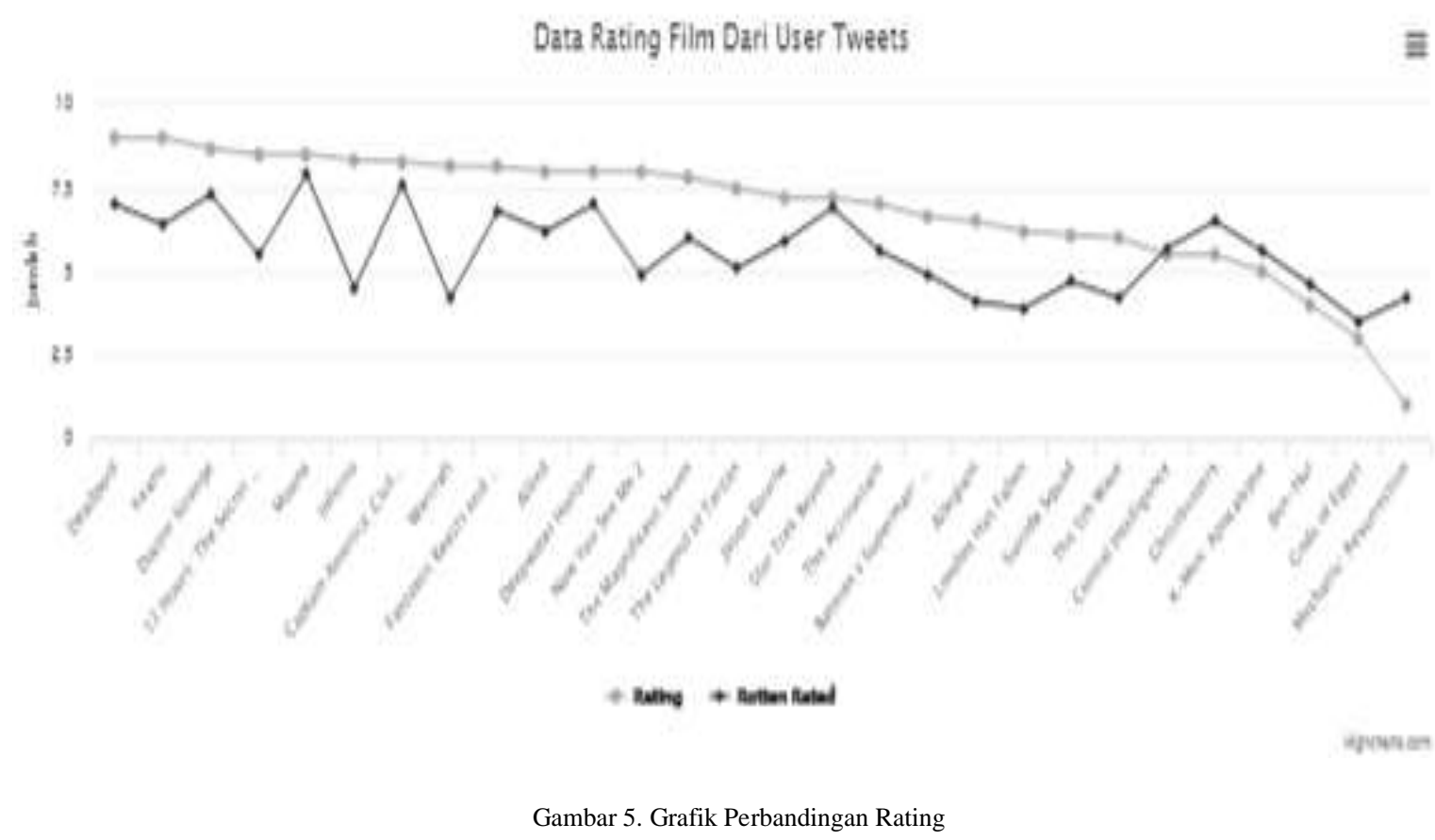

Dari gambar diatas terlihat dalam tabel terdapat row berwarna hijau serta row berwarna merah, baris berwarna hijau merupakan film yang memiliki rating yang sesuai dengan rating yang berasal dari rottentomatoes.com. Sedangkan baris berwarna merah merupakan film yang memiliki rating yang tidak sesuai (memiliki jumlah selisih yang jauh dari rottentomatoes.com > 2). Dengan menghitung jumlah data yang sesuai serta jumlah data yang tidak sesuai, kita dapat menghitung akurasi dari rating yang didapatkan dengan rating yang berasal dari rottentomatoes.com.

Dari tabel diatas didapatkan jumlah keseluruhan data adalah 28 sample dengan 19 film memiliki kesesuaian rating yang tidak terlalu besar sedangkan 9 sisanya memilki kesesuaian rating yang besar, dengan menggunakan rumus validation didapatkan hasil:

$$
\text { Akurasi }=\frac{19}{28} \times 100 \%
$$

\section{Akurasi $=68 \%$}

Dari perhitungan diatas didapatkan bahwa $70 \%$ dari rating yang didapatkan memiliki kesesuaian dengan rating yang berasal dari rottentomatoes.com. Jumlah $68 \%$ merupakan jumlah cukup baik untuk sistem rekomender yang sumber datanya berasal dari tweet user mengenai suatu film. Bukan berasal dari penilaian kritikus film ataupun seseorang yang memiliki pengetahuan dibidang perfilman. 


\section{KESIMPULAN}

Dari hasil pengujian didapatkan kesimpulan sebagai berikut:

1. Dengan menggunakan sumber data yang berasal dari twitter kita dapat memberikan rekomendasi mengenai film yang baik untuk ditonton.

2. Metode SVM serta teknologi IBM Bluemix membuat akurasi dari system rekomendasi film ini lebih dari $50 \%$ atau tepatnya $68 \%$.

\section{DAFTAR PUSTAKA}

[1] N. Monarizqa, L. E. Nugroho, and B. S. Hantono, "Penerapan Analisis Sentimen Pada Twitter Berbahasa Indonesia Sebagai Pemberi Rating," J. Penelit. Tek. Elektro dan Teknol. Inf., vol. 1, pp. 151-155, 2014.

[2] S. Sari and D. T. Hendra, "Aplikasi Rekomendasi Film menggunakan Pendekatan Collaborative Filtering dan Euclidean Distance sebagai ukuran kemiripan rating ISBN : 979-26-0280-1 ISBN : 979-26-0280-1,” pp. 135-140, 2015.

[3] E. K. Putri and T. Setiadi, "Penerapan Text Mining Pada Sistem Klasifikasi Email Spam Menggunakan Naive Bayes," Penerapan Text Min. Pada Sist. Klasifikasi Email Spam Menggunakan Naive Bayes, vol. 2, no. 3, pp. 73-83, 2014, doi: 10.12928/jstie.v2i3.2877.

[4] F. Nurhuda, S. Widya Sihwi, and A. Doewes, "Analisis Sentimen Masyarakat terhadap Calon Presiden Indonesia 2014 berdasarkan Opini dari Twitter Menggunakan Metode Naive Bayes Classifier," J. Teknol. Inf. ITSmart, vol. 2, no. 2, p. 35, 2016, doi: 10.20961/its.v2i2.630.

[5] N. Neneng, K. Adi, and R. Isnanto, "Support Vector Machine Untuk Klasifikasi Citra Jenis Daging Berdasarkan Tekstur Menggunakan Ekstraksi Ciri Gray Level Co-Occurrence Matrices (GLCM),” J. Sist. Inf. Bisnis, vol. 6, no. 1, p. 1, 2016, doi: 10.21456/vol6iss1pp1-10.

[6] R. K. Bakshi, N. Kaur, R. Kaur, and G. Kaur, "Opinion mining and sentiment analysis," in Proceedings of the 10th INDIACom; 2016 3rd International Conference on Computing for Sustainable Global Development, INDIACom 2016, 2016, doi: 10.1561/1500000011.

[7] M. Y. Nur and D. D. Santika, “Analisis Sentimen pada Dokumen berbahasa Indonesia dengan pendekatan Support Vector Machine,” Konf. Nas. Sist. dan Inform., 2011.

[8] S. C. Abadi, R. Chaidir, and G. D. Ramady, "Hal. 38-43 Sistem Pemantauan Kualitas Udara Menggunakan Cloud Application Bluemix, Sarosa Castrena Abadi," ELEKTRA, vol. 4, no. 2, 2019.

[9] N. Dwi Putranti and E. Winarko, “Analisis Sentimen Twitter untuk Teks Berbahasa Indonesia dengan Maximum Entropy dan Support Vector Machine," IJCCS, vol. 8, no. 1, pp. 91-100, 2014. 
JTIULM - Volume 05, Nomor 1, April 2020: 31 - 38 